\title{
Explosion Suppression Control Technology of FG Strong Adsorption Material for Leakage I Flowing Fire of Hazardous Chemicals
}

\author{
Jianshe Huang ${ }^{1}$, Wujun $\mathrm{Hu}^{2}$, Ying Huang ${ }^{3}$, Enlei $\mathrm{Jing}^{4}$, Jianyue $\mathrm{Fu}^{5}$ and Zhimin $\mathrm{Jin}^{5, *}$ \\ ${ }^{1}$ Yongkang emergency Association, Yongkang 321300, China \\ ${ }^{2}$ Yongkang Pesticide Industry Association, Yongkang 321300, China \\ ${ }^{3}$ Yongkang Harmonious Thought Research Association, Yongkang 32100, China \\ ${ }^{4}$ Yongkang enterprise health management Promotion Association, Yongkang 32100, China \\ ${ }^{5}$ Zhejiang University of Technology, Hangzhou 310014, China
}

\begin{abstract}
At present, in the process of production, operation, storage, transportation, use and disposal of petroleum and chemical solvents, major environmental disasters, such as fire, explosion and personal injury caused by leakage, are common. The disasters are often aggravated by the backward emergency disposal technology and improper operation. FG polymer is an inert, strong adsorptive material for hydrophobic substance, and the material is safe itself and non-toxic to aquatic fish and plants. In this study, FG polymer is tested in fire-fighting, explosion suppression and controling flowing fire. The result shows that the FG strong adsorption material can quickly absorb oil spill and leakage of hazardous chemicals on water and land surface, therefore controlling and eliminating the spread of flowing fire, isolating oxygen, extinguishing fire, suppressing explosion, and effectively avoiding environmental pollution. This technology can replace the backward emergency disposal methods such as oil spill dispersant, PP absorbent felt. With this technology being applied in emergence rescue, the disposal cost can be reduced by more than $50 \%$, additionally the abilities of risk prevention, hidden danger elimination, and accident suppression can be enhanced significantly.
\end{abstract}

\section{Introduction}

China is a big chemical country in the world. With the increasing demand for chemical products, China's crude oil output will reach 191 million tons in 2019, and the crude oil processing volume will reach 651.981 million tons ${ }^{[1]}$. By the end of 2018 , the road transportation volume of dangerous goods accounted for $70 \%$ of the total transportation volume of dangerous goods [2].

However, the emergency facilities and materials still can not keep up with the requirements of social development; According to the General Rules for the Storage of Hazardous Chemicals [3] and Requirements for Emergency Rescue Materials of Hazardous Chemicals Units, the backward methods such as sand, lime, activated carbon, PP absorbent

\footnotetext{
*Corresponding author: apharm@sina.com
} 
felt (flammable) and water washing are still used for 60 years. According to the Requirements for Oil Spill Equipment at Ports and Wharves [4], a large number of backward facilities, such as oil spill dispersants, which are easy to pollute the water environment, are still used, which aggravates the damage degree of the ocean, atmosphere, aquatic fish and aquatic plants, and seriously affects the safety of human and urban environment. Therefore, we must pay attention to the source of governance, and really solve the problem in the bud, before the spread [5].

On August 12, 1989, a huge fire and explosion occurred in Huangdao Oil Depot, resulting in 19 deaths and more than 100 injuries [6]. On July 16, 2010, Dalian Xingang oil pipeline exploded, causing a huge ecological disaster [7]. In 2011, the oil spill from Penglai drilling platform polluted the ocean, which was as high as 1.683 billion yuan [8]. On November 22, 2013, the leakage of Qingdao Donghuang oil pipeline resulted in 62 deaths and 136 injuries [9]. In 2015, 165 people were killed, 8 people were missing and 798 people were injured in the explosion in Tianjin port [10]. On April 22, 2016, a fire broke out at No. 2 exchange station in the storage tank area of Jiangsu Deqiao storage Co., Ltd., resulting in the death of a firefighter in the fire fighting [11]. On March 21, 2019, a major explosion occurred in Tianjiayi Chemical Co., Ltd., Xiangshui County, Yancheng, Jiangsu Province, causing 78 deaths and 76 serious injuries[12].

In view of the above defects, this paper proposes a new emergency response technology, which can make up for the shortcomings of emergency skills, and greatly improve the ability of the whole society to deal with emergencies. The FG polymer material has been successfully used in the emergency rescue of hazardous chemical leakage accidents. The technology can quickly absorb oil spills on water and land, control the spread and diffusion of flowing fire, and effectively avoid the pollution of water environment.

\section{Experimental}

\subsection{Experimental materials}

FG adsorption particles are inert polymeric adsorption materials with excellent functions. The adsorption capacity of FG adsorption particles for oil, aromatic, alkane, benzene and ester dangerous chemical liquids is more than 5 times of their own weight, and the maximum is 9 times; The oil retention (oil retention) is $99 \%$. Physical and chemical properties: non combustible, non-toxic, harmless, resistant to $800^{\circ} \mathrm{C}$ high temperature, resistant to $-50^{\circ} \mathrm{C}$ low temperature, stable chemical properties, no oxidation, acid and alkali resistance, corrosion resistance.

FG adsorption particles have a special nano micropore pore structure. The porosity of adsorption and storage is $95 \%$, and the specific surface area is $300 \mathrm{~m}^{2} / \mathrm{g}$, the $\mathrm{pH}$ value is neutral, the micropore structure has super strong physical adsorption force field, fast adsorption rate, and complete oil-water separation. The adsorption mode of FG particles is physical adsorption. The dangerous chemical liquid floating on the water surface absorbed by the material quickly becomes a solid, and the water surface immediately recovers to be clean.

\subsection{Experimental methods}

Four stainless steel tanks with an area of $1 \mathrm{~m}^{2}$ were placed in the water layer of $20 \mathrm{~cm}$, each tank was filled with 2 liters of 0 \# diesel oil, and the oil film thickness was about $2 \mathrm{~mm}$. The adsorption material was put into the tank, and the metal rod was stirred for 10 minutes. After 20 minutes, the experimental and control materials were filtered out until there was 
no oil drop. If there is oil film on the water surface, continue to put adsorption materials. If there is no oil film on the water surface, there is no need to put adsorption materials. The amount of adsorbent in each treatment was calculated according to the oil absorption. The control materials were inorganic adsorption particles, marine oil absorbing felt and aerogel adsorbent without duplication. The residual amount of diesel oil adsorbed on water surface was investigated, expressed in $\mathrm{ml} / \mathrm{m}^{2}$. The test method of oil absorption and oil retention is in accordance with GB6504-2008. The oil content of water surface is directly determined by nuclear magnetic resonance oil content analyzer.

\subsection{Experimental results}

According to Table 1, the material cost, labor cost and total cost of FG adsorption particles in the experimental group are far less than those in the conventional adsorption particle control group, the marine oil absorbing felt control group and the aerogel adsorbent control group. In addition, the residual amount of diesel oil on the water surface reached 0.05 $\mathrm{ml} / \mathrm{m}^{2}$ at the first time. The experimental results in Table 1 show that the oil retention of the adsorption material is the index of the oil absorption removal effect and cost when the oil film thickness is $2 \mathrm{~mm} / \mathrm{m}^{2}$ and the oil content is $2 \mathrm{~L} / \mathrm{m}^{2}$. 


\begin{tabular}{|c|c|c|c|c|}
\hline$\vec{a}$ & $\dot{a}$ & $\begin{array}{l}n \\
\hat{Q}\end{array}$ & $\overrightarrow{\bar{T}}$ & 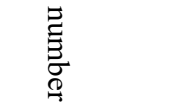 \\
\hline 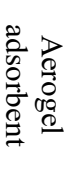 & 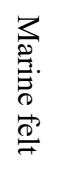 & 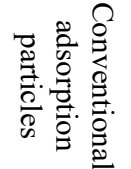 & 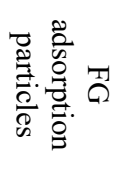 & 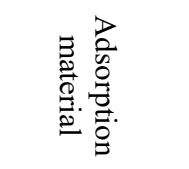 \\
\hline 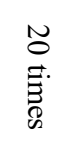 & $\begin{array}{l}\overrightarrow{0} \\
\vec{E} \\
0 \\
0\end{array}$ & $\begin{array}{l}u \\
\text { 它. } \\
\stackrel{0}{0}\end{array}$ & $\begin{array}{l}u \\
\vec{E} \\
\vec{D}_{0}\end{array}$ & 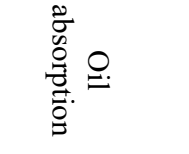 \\
\hline$\stackrel{\infty}{\circ}$ & $\stackrel{\infty}{\circ}$ & ڤे & $\begin{array}{l}: \\
: 0 \\
: 0\end{array}$ & 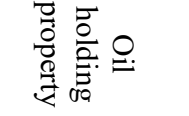 \\
\hline$\underset{\mathrm{Q}}{\mathrm{a}}$ & $\underset{\substack{\mathscr{O} \\
\text { Oa }}}{ }$ & 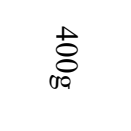 & 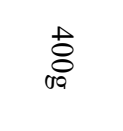 & 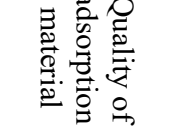 \\
\hline 㕝 & 今े & $\stackrel{\infty}{8}$ & $\stackrel{\circ}{\circ}$ & $\underset{0}{T}$ \\
\hline$\ddot{\infty}$ & 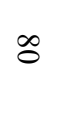 & 诖 & 0 & 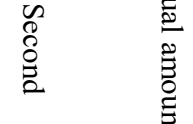 \\
\hline$\sigma$ & $\sigma$ & $\underset{\infty}{\bar{\infty}}$ & 0 & 㐭 $\quad$ 总 \\
\hline$\stackrel{w}{i}$ & $\stackrel{w}{i}$ & $\stackrel{u}{i}$ & 0 & 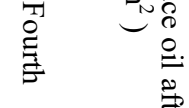 \\
\hline$\dot{i}$ & $\stackrel{\vec{i}}{\dot{\perp}}$ & $\tilde{\sigma}$ & 0 & 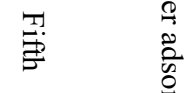 \\
\hline$\underset{\substack{i \\
\infty}}{\substack{+\infty}}$ & 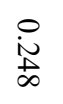 & 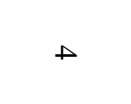 & 0 & 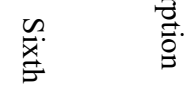 \\
\hline$\underset{\mathrm{o}}{0}$ & 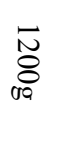 & 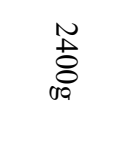 & $\underset{\square}{+}$ & 壭. \\
\hline$\vec{\varkappa}$ & $\stackrel{w}{*}$ & ఖి & $\approx$ & 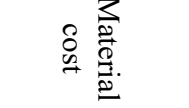 \\
\hline$\stackrel{\approx}{\approx}$ & $\stackrel{\approx}{\approx}$ & $\curvearrowright$ & $\approx$ & 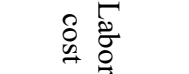 \\
\hline
\end{tabular}




\section{Successful rescue case of FG strong adsorption material}

In July 15, 2016, 16 tons of oil leaked from the oil tank truck of Yongkang section of G25 Changshen Highway [13]. FG adsorption particles/mats were used successfully in protecting the fishery, water area and urban environment on both sides of Qiantang River (Fig. 1).

A

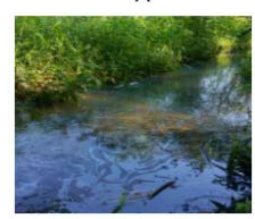

B

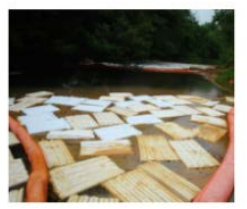

C

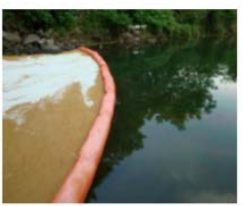

Fig. 1. Emergency treatment of "7.15" Changshen high speed engine oil leakage accident:
A. Oil Contaminated Farmland
B. Oil pollution treatment
C. Treatment effect

At 10:00 a.m. on April 12, 2020, an unidentified chemical leakage accident occurred at the exit ramp of Yongkang Fangyan on S27 Dongyong Highway [14]. The polluted water surface is about 7000 square meters. More than ten tons of chemical liquid discharged to the diversion canal of Xuetang village, Fangyan town (300 meters into the central cellar canal), endangering the risk of gas volatilization and explosion. In accordance with $Q / Y Z Y$ Technical Specification for Emergency Disposal of Hazardous Chemicals Leakage [15], FG adsorption particles/mats were put into operation to cover and block all of them, so as to reduce the hazard of harmful gas evaporation, avoid a malignant accident of secondary explosion risk, and remove more than 20 tons of wastes in the whole process (Fig. 2).
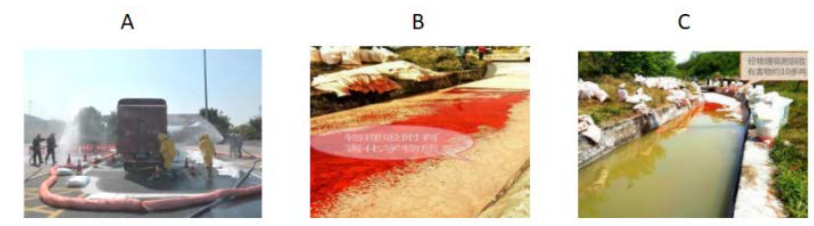

Fig. 2. Emergency treatment of chemical leakage accident of "4.12" Dongyong Highway:
A. Accident scene,
B. Fire and explosion suppression treatment.
C. Treatment effect

\section{Application measures and precautions of FG adsorption material}

\subsection{Ground oil spill emergency measures and precautions}

First of all, FG adsorption trawl with strong adsorption, fire prevention and explosion suppression were laid on the gas station, oil storage depot and oil spill surface to prevent pollutants from diffusing into restricted spaces such as sewers, drainage ditches, external waters and soil.

In case of a large amount of leakage, FG adsorption trawl with strong adsorption, fire prevention and explosion suppression shall be laid around the oil storage tank to drain the spilled oil into the emergency pool or dig a pit to receive sewage and block it to prevent diffusion, and FG oil absorption particles shall be covered to control oil evaporation and 
avoid secondary combustion and explosion accidents. It should be noted that it is not allowed to wash with water or neutralize with sand or discard anywhere to avoid secondary expansion of environmental pollution.

\subsection{Emergency measures and precautions for water ecological environment}

When controlling the oil spill and endangering the ecological environment of the water area, FG adsorption trawl should be put by the ship to prevent the non-proliferation. When the river cannot be intercepted, XTL-FGY150-200 type adsorption trawlers are arranged at the upstream position with relatively stable flow, horizontally connected and blocked with hooks, and no less than 3-5 FG adsorption trawlers are set respectively to avoid oil spill drift endangering the downstream or surrounding waters.

In accordance with Marine Environmental Protection Law, Water Pollution Prevention Law, and Measures of the People's Republic of China for the Prevention and Control of Ship Pollution of River Water Environment [16], strictly abide by the guidelines for Use of Oil Spill Dispersant [17], prohibit the use of oil spill dispersant in sensitive waters such as coastal waters, inland rivers, lakes and drinking water reservoirs, and avoid major disasters and accidents in secondary and derivative water environment, aquatic fish and urban environment, Maintain social harmony and healthy development.

\section{Conclusion}

FG adsorption material has obvious advantages in dealing with major accidents such as flowing fire. The cost of FG oil absorption trawler is less than $30 \%$ of that of oil containment trawler. It is easy to put into operation, and does not need to be inflated and powered, which does not affect the passage of small boats. If the spilled area is large, the trawler can be surrounded to reduce the area and then fished to make the oil absorbing particles easy to recover. In addition, the adsorbed particles are still in a solid state after adsorbing the oil spill pollutants, which is convenient for cleaning, collection and bagging, away from the site, and avoids the generation of secondary pollution.

FG adsorption material is suitable for all kinds of organic matter leakage accidents. According to the successful cases of this experiment and the application of FG adsorption materials, the material cost, labor cost and total cost of FG adsorption particles are far less than that of conventional adsorption particles, marine felt and aerogel adsorbent, which greatly reduces the economic cost of dealing with fire.

The correct application of FG strong adsorption material will help to improve the management level of urban safety production, improve the scientific level and ability of emergency disposal of hazardous chemicals, and reduce the negative impact of emergency disposal of hazardous chemicals on environmental protection.

\section{References}

[1] Zhiqiang, L. No affiliated operation of dangerous goods transport vehicles. People's daily, (2019).

[2] Bo, P. The Ministry of transport circulates the relevant contents of Measures for the Administration of Road Transport Safety of Dangerous Goods and answers questions. Ministry of transport, (2020).

[3] GB15603-1995, General Rules for Storage of Hazardous Chemicals. 
[4] China traffic industry standard JT/T451-2009, Requirements of Oil Spill Equipment in Port and Wharf.

[5] Bao-cheng, M. Establish the public security hidden danger investigation and safety prevention and control system. Party School of the CPC Central Committee, (2020).

[6] On August 12, 1989, the Huangdao Oil Depot was struck by lightning, caught fire and exploded. Extraordinary daily, (2020).

[7] Chong-hang, T. Explosion site in Dalian Xingang: oil pipe is still leaking. New Beijing News, (2010).

[8] CNOOC Bohai Bay oil spill in 2011. Safety management network, (2018).

[9] Investigation report on leakage and explosion accident of Sinopec Donghuang oil pipeline. China government website, (2014).

[10]A particularly serious fire and explosion accident in Ruihai dangerous goods warehouse on August 12, Tianjin Port. Safety management network, (2020).

[11]Jiangsu Deqiao storage Co., Ltd. Investigation on the causes of "4-22" major fire accident and preventive measures. Emergency management in China, (2016).

[12] Spontaneous combustion caused by long term illegal storage of hazardous waste. Report on investigation of the explosion of sound water in Jiangsu Province. Agricultural chemical market news, (2019).

[13]Wujun, H. Escorting G20 summit in Hangzhou. Emergency management in China, (2018).

[14] The middle wing rescue team of Yongkang pioneer civil defense rescue team is in emergency. Tencent, (2020).

[15]Q/YZY301-2019, Technical specification for emergency disposal of hazardous chemicals leakage.

[16] Measures of the people's Republic of China for the prevention and control of pollution of river water by ships. Order No.25 of the Ministry of communications in 2015, (2015)

[17]CB18188.1-2000, Oil Spill Dispersant. 